\title{
The Role of Retained Austenite on Tensile Properties of Steels with Bainitic Microstructures
}

\author{
Carlos García-Mateo and Francisca G. Caballero \\ Department of Physical Metallurgy. Materalia Research Group. Centro Nacional de Investigaciones Metalúrgicas (CENIM-CSIC), \\ Avda. Gregorio del Amo, 8, 28040, Madrid, Spain
}

In high-carbon, silicon-rich steels it is possible to obtain a very fine bainitic microstructure by transformation at low temperatures (200$300^{\circ} \mathrm{C}$ ). This microstructure consists of slender ferrite plates, with thicknesses of several tens of nm, in a matrix of retained austenite. Whereas strength is mainly provided by to the fine scale of the ferrite plates (stronger phase), ductility is mostly controlled by the retained austenite (softer phase). Further improvement in ductility is achieved by strain induced transformation of austenite to martensite, the so called TRIP effect. In order to take full advantage of this effect, the mechanical stability of the austenite, i.e., its capability to transform to martensite under strain, must not be too low nor excessively high.

Two main aspects of the mechanical stability of the retained austenite, morphology and chemical composition, have been studied to determine the role that these play on the ductility behaviour of the bainitic steels studied. It is suggested that the chemical composition has the strongest effect on the ductility of these new high strength alloys.

(Received March 1, 2005; Accepted June 8, 2005; Published August 15, 2005)

Keywords: Bainite, retained austenite, mechanical stability, morphology, chemical composition, ductility, strength

\section{Introduction}

By means of phase transformation theory for the bainite reaction, high-carbon, silicon-rich steels have been developed $^{1,2)}$ with bainite transformation temperatures as low as $T / T_{\mathrm{m}} \cong 0.25$, where $T_{\mathrm{m}}$ is the absolute melting temperature. The resulting microstructure consists of aggregates of fine plates of bainitic ferrite separated by untransformed carbonenriched austenite. The aggregates of plates are called sheaves, whereas the plates within each sheaf are defined as subunits; the subunits within the same sheaf share a common crystallographic orientation. Thus, two retained austenite morphologies exist: thin films between ferritic subunits and blocks separating the sheaves. Carbide precipitation is avoided by the judicious use of silicon as an alloying element.

This mixed microstructure presents an ideal balance of mechanical properties from many points of view. Due to the absence of fine carbides, the steels have a high resistance to cleavage fracture and void formation. Then, there is the possibility of improving simultaneously the strength and toughness because of the ultrafine grain size $(20-40 \mathrm{~nm})$ of the bainitic ferrite plates and of further enhancing the ductility by a transformation induced plasticity effect $(\mathrm{TRIP})^{3)}$ that increases the strain-hardening rate.

It is well established that the strain induced transformation of austenite to martensite takes place between the $M_{\mathrm{S}}$ temperature (martensite start temperature), and the $M_{\mathrm{d}}$ temperature, above which the austenite becomes completely stable. Therefore, there is a temperature between $M_{\mathrm{S}}$ and $M_{\mathrm{d}}$ at which the strain induced transformation is suppressed moderately and the resultant strain hardenability is held in a large strain range, leading to maximum benefit of the TRIP effect. At low test temperatures or in alloys which have austenite of low mechanical stability, the strain-induced transformation occurs in early stages of deformation. As a result, there is little benefit of the strain hardening related to deterring plastic instability or necking in the later stages of deformation. On the other hand, at high temperatures, the austenite becomes mechanically more stable and transforms at higher strains, hence the associated strain hardening effectively increases resistance to necking and fracture. At even higher temperatures, i.e. above that where no straininduced transformation occurs $\left(M_{\mathrm{d}}\right)$ ductility is reduced. So, the strain induced transformation will enhance ductility if retained austenite is moderately stable against straining. On the other hand, the presence of large amounts of stable austenite at necking (instability criterion) does not guarantee enhanced ductility if that austenite is too stable. The mechanical stability of the austenite is controlled by its chemical composition (both $M_{\mathrm{d}}$ and $M_{\mathrm{S}}$ temperatures depend on the chemical composition) and its morphology (in blocks or thin films), as will be detailed further on. The purpose of this work is to evaluate the stability of the retained austenite and its influence on the ductility of steels with bainitic microstructure.

\section{Materials and Experimental Procedure}

The chemical compositions of the alloys used are listed in Table 1. Detailed information on the metallurgical design of the alloys and of the heat treatment is given elsewhere. ${ }^{4)}$ After homogenising lumps of the material at $1200^{\circ} \mathrm{C}$ during 2 days, a slow cooling rate to room temperature was applied in order to avoid martensitic transformation, since the highcarbon martensite plates tend to crack spontaneously, permanently compromising the integrity of the sample. To obtain the bainitic microstructure, austenitisation at $900^{\circ} \mathrm{C}$ for $30 \mathrm{~min}$ prior to an isothermal heat treatment at 200, 250

Table 1 Chemical composition in mass $\%$.

\begin{tabular}{lccccccccc}
\hline & $\mathrm{C}$ & $\mathrm{Si}$ & $\mathrm{Mn}$ & $\mathrm{Mo}$ & $\mathrm{Cr}$ & $\mathrm{Co}$ & $\mathrm{Al}$ & $\mathrm{P}$ & $\mathrm{S}$ \\
\hline Alloy 1 & 0.80 & 1.59 & 2.01 & 0.24 & 1 & 1.51 & - & 0.002 & 0.002 \\
Alloy 2 & 0.79 & 1.56 & 1.98 & 0.24 & 1.01 & 1.51 & 1.01 & 0.002 & 0.002 \\
\hline
\end{tabular}


and $300^{\circ} \mathrm{C}$ was applied. Finally samples were water quenched to room temperature.

X-ray experiments were conducted using a Phillips PPW1730 diffractometer and a scanning rate $(2 \theta)$ of $0.1^{\circ} \mathrm{min}^{-1}$ over the range $2 \theta=30-110^{\circ}$, with unfiltered $\mathrm{Cu} \mathrm{K} \alpha$ radiation. The system was operated at $45 \mathrm{kV}$ and $45 \mathrm{~mA}$. The retained austenite content was calculated using integrated intensities of the 111, 200, 220 and 311 austenite peaks and the 110, 002, 112 and 022 peaks of ferrite. Using this number of peaks avoids possible bias due to crystallographic texture.5) The austenite carbon content $\left(C_{\gamma}\right)$ was calculated making use of the relationship between lattice parameter and chemical composition as reported in Ref. 6).

The martensite start temperature $\left(M_{\mathrm{S}}\right)$ of the retained austenite present in the bainitic microstructures was calculated by means of the latest neural network model. ${ }^{7,8)}$ The $M_{\mathrm{d}}$ temperature was calculated using eq. (1). ${ }^{9)}$ Both temperatures, $M_{\mathrm{S}}$ and $M_{\mathrm{d}}$, give an indication of the thermal and mechanical stability, respectively, of the retained austenite.

$$
\ln V_{\gamma}^{0}-\ln V_{\gamma}=k_{1} \Delta G^{\alpha^{\prime} \gamma} \varepsilon
$$

where $V_{\gamma}^{0}$ and $V_{\gamma}$ represent the initial austenite fraction and the remaining fraction, after transformation induced plasticity, respectively. Therefore $M_{\mathrm{d}}$ corresponds to the temperature at which $V_{\gamma}^{0}=V_{\gamma} ; \mathrm{k}_{1}$ is a constant, $\varepsilon$ is the plastic strain and $\Delta G^{\alpha^{\prime} \gamma}$ represents the chemical free energy change for the transformation of austenite to ferrite of the same composition. The free energy change calculations were carried out using MTDATA with the NPL-plus data base for steels. ${ }^{10)}$

Due to the very low transformation temperatures, during the time scale of the experiments, an $\mathrm{Fe}$ atom cannot diffuse over a distance greater than $\sim 10^{-17} \mathrm{~m}$, it is reasonable to explain this bainitic transformation in the context of the Bhadeshia theory ${ }^{11)}$ for the bainitic reaction. According to this theory nucleation of bainite takes place under paraequilibrium conditions (only $\mathrm{C}$ diffuses) and growth is diffusionless. Therefore, for the calculation of both temperatures, $M_{\mathrm{S}}$ and $M_{\mathrm{d}}$, the retained austenite composition was calculated using the carbon concentration provided by X-ray diffraction and keeping in mind that after transformation only $\mathrm{C}$ has diffused. Thus, the concentration ratios of all elements but $\mathrm{C}$ should be equal in the bulk material as in the retained austenite $(\gamma)$; in other words, $\left(x_{\mathrm{Fe}} / x_{j}\right)_{b u l k}=\left(x_{\mathrm{Fe}} / x_{j}\right)_{\gamma}$, where $j$ denotes any substitutional element in the alloy, and $x_{\mathrm{Fe}}$ and $x_{j}$ are the concentrations of $\mathrm{Fe}$ and of the substitutional elements, respectively.

Tensile specimens with a section of $5 \mathrm{~mm}$ diameter and a gauge length of $25 \mathrm{~mm}$ were tested at room temperature using an Instron- 8032 fitted with a $100 \mathrm{kN}$ load cell. A crosshead speed of $0.1 \mathrm{~mm} / \mathrm{min}$ was used in all the experiments. All mechanical experiments were assisted by electronic equipment that allowed the continuous tracking of load-displacement data during tests. All samples were machined from the softened (pearlitic) bulk material after homogenization and subsequently heat treated to the desired conditions. Load and elongations measured during uniaxial tensile tests were converted to engineering and true stress-strain curves. Strain hardening was characterized by the incremental strainhardening exponent defined as $n=\mathrm{d}(\ln \sigma) / \mathrm{d}\left(\ln \varepsilon_{p}\right)$, where $\sigma=k \varepsilon_{p}^{n}$ represents the flow curve in the region of uniform true plastic deformation and $\mathrm{k}$ is the strength coefficient.

Specimens for transmission electron microscopy were prepared by slicing $100 \mu \mathrm{m}$ discs and grinding them down to $50 \mu \mathrm{m}$ thickness using 1200 grit silicon carbide paper. Subsequently they were electropolished at $50 \mathrm{~V}$ in a twin jet unit, using an electrolyte that consisted of 5\% perchloric acid, $15 \%$ glycerol and $80 \%$ ethanol in volume. Samples were extracted from tensile test grips and from the gauge length away from the fracture/necking zone, in order to characterise the undeformed and deformed states of the microstructure.

\section{Results}

\subsection{Microstructural characterization}

Figure 1 shows the typical microstructure obtained once bainitic transformation has ceased. As mentioned above, it consists of a mixture of two phases, plates of bainitic ferrite separated by carbon enriched regions of austenite. In this figure several examples of both types of retained austenite morphologies can be observed: blocky austenite between the sheaves of bainite and thin films between the plates. Figures 1(a) and (b) show optical micrographs of the microstructure obtained at the end of the transformation at $200^{\circ} \mathrm{C}$ for both alloys. The lighter phases are blocks of retained austenite, whereas the darker feather-like features are sheaves of bainite. Only by means of transmission electron microscopy it is possible to observe the bainitic ferrite plates (light phase) and the retained austenite thin films (dark phase), as shown in Figs. 1(c) and (d).

Although detailed microstructural characterisation of bainitic ferrite plates has been performed elsewhere, ${ }^{4,12)}$ it is worth to emphasize some relevant features of it. Firstly, the small thickness of the ferrite plates becomes coarser as the transformation temperature increases, about 30 and $65 \mathrm{~nm}$ for alloy 1 and 45 and $54 \mathrm{~nm}$ for alloy 2 in the microstructures obtained at 200 and $300^{\circ} \mathrm{C}$ respectively. This is a consequence of the increased strength of the parent austenite at low temperatures and the magnitude of the free energy change accompanying transformation. The second feature is the large amount of carbon, up to 0.35 mass $\%$, which remains trapped inside the bainitic ferrite. ${ }^{12-14)}$ It has been suggested that the excess carbon is located at defects such as dislocations in the vicinity of the ferrite/austenite interface. ${ }^{15,16)}$

Table 2 summarises experimental data concerning the microstructure as a function of transformation temperature. The microstructures are predominantly ferritic, up to 0.87 ferrite fraction at $200^{\circ} \mathrm{C}$, with decreasing austenite fractions as the transformation temperature is reduced. It is well established ${ }^{17)}$ that bainitic microstructures formed at low temperatures contain retained austenite mainly with thin film morphology. This is related to the higher bainitic ferrite fraction reached at low transformation temperatures. It is possible to estimate the fraction of thin films $\left(V_{\gamma_{\mathrm{F}}}\right)$ and blocks $\left(V_{\gamma_{\mathrm{B}}}\right)$ as a function of the bainite transformation temperature following Ref. 17), as shown in Table 2. In this table it can be seen that that alloy 1 exhibits higher or equal fractions of $V_{\gamma_{\mathrm{F}}}$ when compared with alloy 2 . In terms of its mechanical stability, thin films of retained austenite (few nm thickness) 

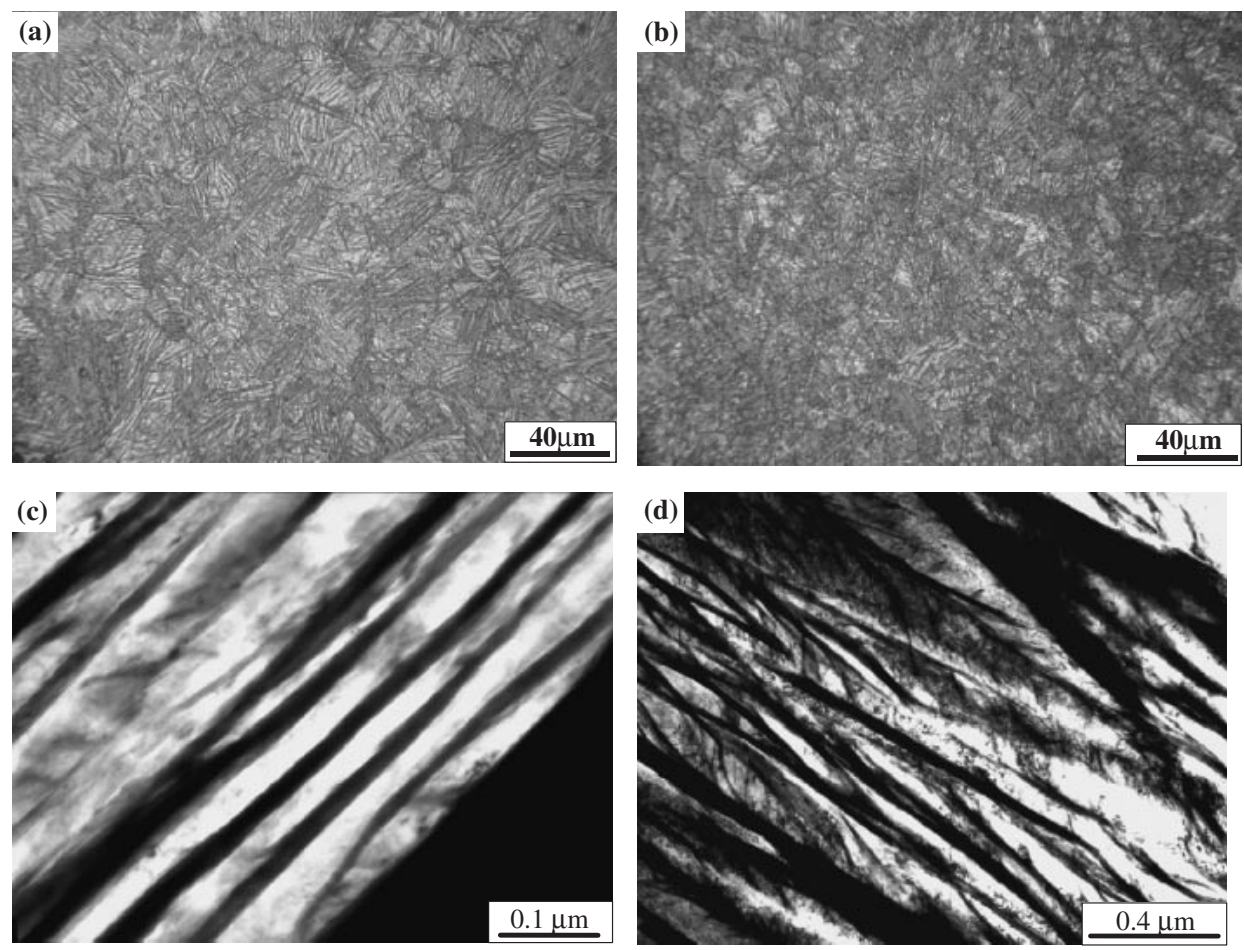

Fig. 1 Optical and transmission electron micrographs of alloy 1, (a) and (c), and alloy 2, (b) and (d), after bainitic transformation at $200^{\circ} \mathrm{C}$.

Table 2 Retained austenite characterization data. $T$ stands for the isothermal transformation temperature, $C_{\gamma}$ for the austenite carbon concentration, $M_{\mathrm{S}}$ and $M_{\mathrm{d}}$ for the martensite start temperature and the temperature above which no strain induced transformation is possible, respectively. $V_{\gamma}$ stands for the total retained austenite fraction, by means of X-ray. $V_{\gamma_{\mathrm{F}}}$ and $V_{\gamma_{\mathrm{B}}}$ are the fractions of thin films and blocks of retained austenite, respectively, according to Ref. 17.

\begin{tabular}{|c|c|c|c|c|c|c|c|}
\hline & $T /{ }^{\circ} \mathrm{C}$ & $C_{\gamma} / \mathrm{mass} \%$ & $V_{\gamma}$ & $V_{\gamma \mathrm{F}}$ & $V_{\gamma_{\mathrm{B}}}$ & $M_{\mathrm{S}} /{ }^{\circ} \mathrm{C}$ & $M_{\mathrm{d}} /{ }^{\circ} \mathrm{C}$ \\
\hline \multirow[b]{2}{*}{ Alloy 1} & 200 & 1.1 & 0.13 & 0.129 & 0.0001 & -10 & 391 \\
\hline & 250 & 1.4 & 0.21 & 0.12 & 0.09 & -35 & 301 \\
\hline \multirow{3}{*}{ Alloy 2} & 200 & 1.47 & 0.17 & 0.123 & 0.04 & 16 & 321 \\
\hline & 250 & 1.7 & 0.21 & 0.12 & 0.09 & -10 & 251 \\
\hline & 300 & 1.9 & 0.37 & 0.09 & 0.28 & -27 & 221 \\
\hline
\end{tabular}

are too stable ${ }^{18,19)}$ to transform by TRIP effect, in part because of their high carbon concentration ${ }^{20)}$ and also because of the constraint to transformation exerted by the surrounding plates of ferrite. On the other hand, blocks of austenite, which contain less carbon than the thin films, are less stable.

Due to the low transformation temperatures and the intrinsic characteristics of the bainite transformation, i.e., paraequilibrium nucleation and diffusionless growth, the average carbon concentration in retained austenite, $C_{\gamma}$, is above 1 mass $\%$, thereby stabilising it down to ambient temperature after isothermal treatment. This is supported by the fact that no martensite is detected by means of X-ray and that the estimated retained austenite $M_{\mathrm{S}}$ temperatures are below room temperature.

As mentioned above, strain induced transformation occurs in a temperature range between $M_{\mathrm{S}}$ and $M_{\mathrm{d}}$, above which no transformation takes place. Both temperatures depend on the retained austenite chemical composition. Elements such as $\mathrm{C}$, $\mathrm{Mn}, \mathrm{Si}$ and $\mathrm{Al}^{21,22)}$ significantly affect the mechanical stability of austenite by decreasing $M_{\mathrm{d}}$ and/or $M_{\mathrm{S}}$. Among them $\mathrm{C}$ is the element that exhibit the strongest influence. Calculated $M_{\mathrm{d}}$ temperatures are summarised in Table 2. It is important to highlight what a high or low value of $M_{\mathrm{d}}$ temperature implies in terms of mechanical stability and of the efficiency in enhancing ductility. This becomes clear in Fig. 2(a). By means of eq. (1) the fraction of retained austenite transformed by the TRIP-effect at room temperature as a function of plastic strain has been calculated for alloy 2 transformed at different temperatures. It is evident that a high $M_{\mathrm{d}}$ temperature leads to a less stable austenite (fast transformation), and thus reduces the beneficial effect of strain induced transformation on ductility in this steel. In Fig. 2(b) the influence of the test temperature on the mechanical stability of retained austenite is shown. As expected, as the test temperature is increased austenite becomes more stable, due to the lower transformation rate.

Thus, and according to the calculated $M_{\mathrm{d}}$ temperatures in Table 2, the retained austenite in alloy 2 is mechanically more stable, meaning lower $M_{\mathrm{d}}$ temperatures, than in alloy 1 , 

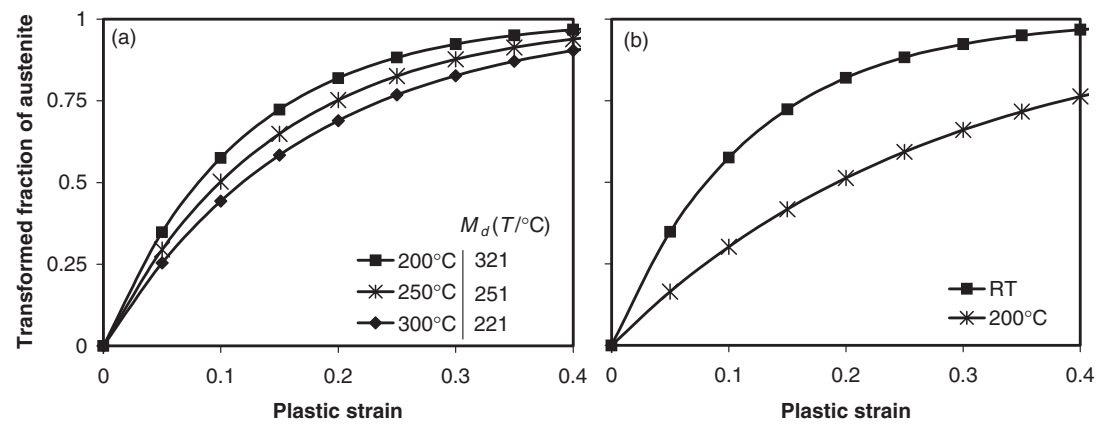

Fig. 2 Transformed fraction of austenite ${ }^{9)}$ in alloy 2 vs. plastic strain, a) calculations for the bainitic microstructures developed at isothermal temperatures of 200,250 and $300^{\circ} \mathrm{C}$ and tested at room temperature, b) calculations for the microstructure obtained after isothermal transformation at $200^{\circ} \mathrm{C}$ and tested at room temperature $(R T)$ and at $200^{\circ} \mathrm{C}$.

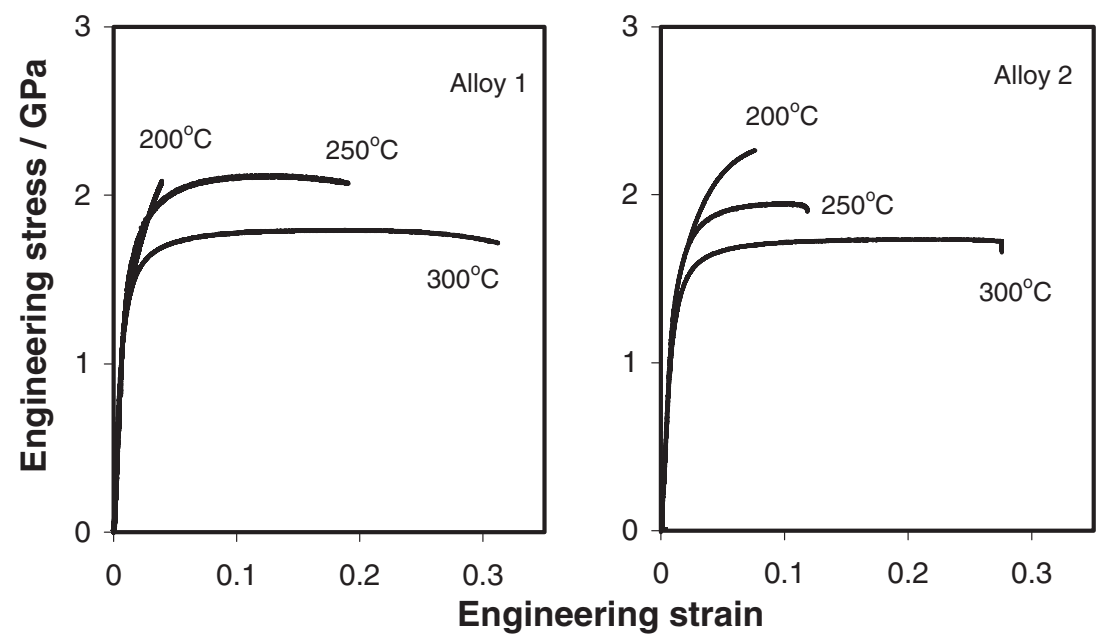

Fig. 3 Engineering stress-strain curves at room temperature, of microstructures obtained after transformation at the temperatures indicated.

Table 3 Summary of experimental data from tensile tests at room temperature. $T$ stands for the isothermal transformation temperature and $\varepsilon_{\mathrm{T}}$ for the total elongation.

\begin{tabular}{ccccc}
\hline & $T /{ }^{\circ} \mathrm{C}$ & $Y S / \mathrm{GPa}$ & $U T S / \mathrm{GPa}$ & $\varepsilon_{\mathrm{T}} / \%$ \\
\hline \multirow{3}{*}{ Alloy 1 } & 200 & 1.41 & 2.18 & 4.6 \\
& 250 & 1.48 & 2.06 & 19 \\
& 300 & 1.24 & 1.77 & 29 \\
\hline \multirow{3}{*}{ Alloy 2 } & 200 & 1.41 & 2.26 & 7.63 \\
& 250 & 1.40 & 1.93 & 9.4 \\
& 300 & 1.25 & 1.7 & 27.5 \\
\hline
\end{tabular}

because of its higher $\mathrm{C}$ concentration, and, moreover, because it contains about 1.01 mass $\% \mathrm{Al}$ of which alloy 1 lacks, see Table 1.

\subsection{Mechanical properties}

Figure 3 shows the measured strain-stress curves, from tensile tests at room temperature, of microstructures obtained after transformation at 200,250 and $300^{\circ} \mathrm{C}$ for both alloys. The results obtained are listed in Table 3, showing an extraordinary combination of tensile properties. Yield strengths $(Y S)$ are greater than $1.2 \mathrm{GPa}$ and ultimate tensile strengths (UTS) are ranging from 1.77 to $2.2 \mathrm{GPa}$. Ductility, measured as total elongation $\left(\varepsilon_{\mathrm{T}}\right)$, decreases as the strength increases. The microstructures obtained by transformation at $300^{\circ} \mathrm{C}$ exhibit a total elongation close to $30 \%$ for both alloys, very high values when compared with those obtained by transformation at $200^{\circ} \mathrm{C}$, where the elongation is reduced to 4.6 and $7.6 \%$ for alloys 1 and 2, respectively. Figure 4 represents the strength $v s$. total elongation for bainitic steels from the literature ${ }^{23-25)}$ and for those studied in this work. It can be clearly seen that the tensile properties reported in this work has never before been achieved in bainitic steels.

It has been suggested ${ }^{12)}$ that in this type of low temperature bainitic microstructures the main strengthening mechanism is intimately related to the very small thickness of the ferrite plates and to its high dislocation density. The former gives the largest contribution, up to $1.6 \mathrm{GPa}$, while a maximum of $500 \mathrm{MPa}$ is estimated to be provided by the dislocation density. ${ }^{26)}$

On the other hand, ductility seems to be controlled by the amount of retained austenite, which is the softest phase present in the microstructure. Thus, the microstructures obtained after isothermal heat treatment at $300^{\circ} \mathrm{C}$, with austenite fractions of 0.25 and 0.37 for alloys 1 and 2 respectively, exhibit the best results in terms of total elongation when compared with stronger microstructures obtained after transformation at lower temperatures, i.e., with lower retained austenite content. 

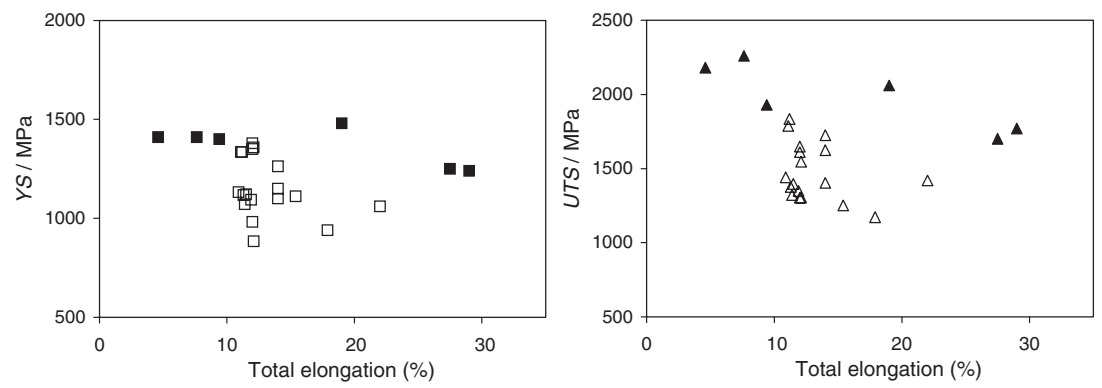

Fig. 4 Comparison of tensile properties between bainitic steels from Refs. 23-25 (open symbols) and those reported in this work (solid symbols).
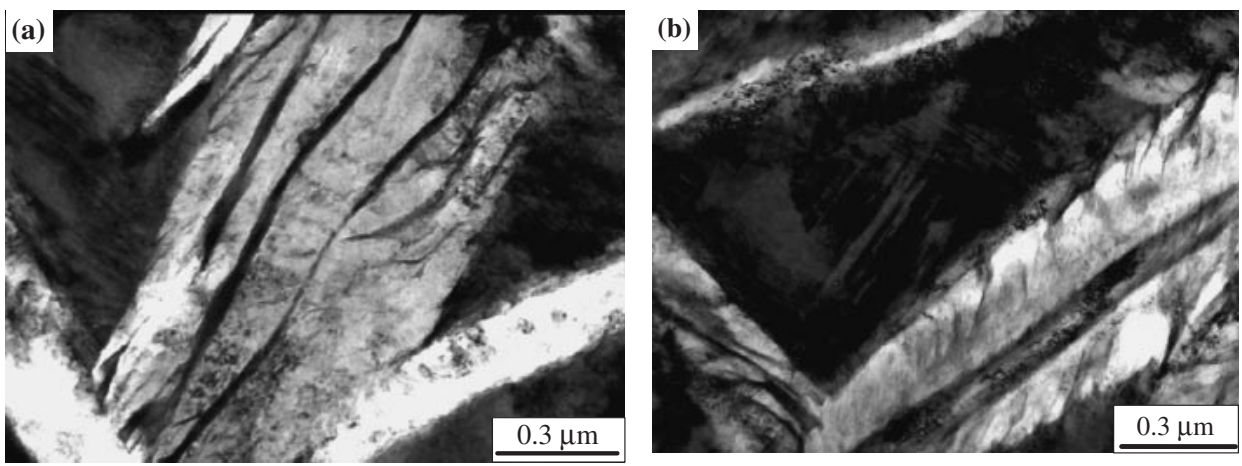

Fig. 5 Transmission electron micrographs showing bainitic microstructures formed at $200^{\circ} \mathrm{C}$ after completion of the tensile test at room temperature, (a) alloy 1 and (b) alloy 2.
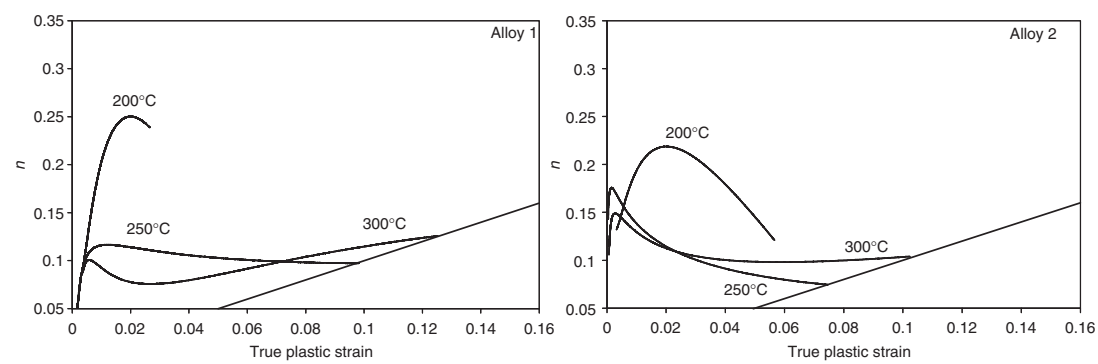

Fig. 6 Curves of the incremental work hardening exponent, $n$, of bainitic microstructures obtained by transformation at different temperatures $\left(200,250\right.$ and $\left.300^{\circ} \mathrm{C}\right)$ and tested at room temperature. The straight line represents the instability criterion.

Some examples of the microstructures after completion of tensile testing are shown in Fig. 5. Evidence of plastic deformation of ferrite plates can be observed in Fig. 5(a), and a clear example of the TRIP effect in Fig. 5(b), where martensite twinning bands appears in former blocks of retained austenite. Dislocation debris is evident in both the bainitic ferrite and the surrounding, recently formed martensite.

\section{Discussion}

Figure 6 presents the variation of the incremental work hardening exponent $n$ as a function of true strain. The straight line corresponds to the instability criterion $\varepsilon_{p}=n$. It appears that the different strength-ductility combinations are associated with completely different work-hardening behaviours. The large true uniform strains of specimens treated at $300^{\circ} \mathrm{C}$ are due to a high retained austenite fraction that continuously increases the incremental work-hardening $n$ after a sharp decrease at low plastic strains. In this sense, alloy 1 exhibits a remarkable recovery in comparison with alloy 2 . The microstructures obtained by transformation at $250^{\circ} \mathrm{C}$ show a different behaviour in the two alloys. In alloy 1 , after reaching a maximum $n$ smoothly decreases until the onset of necking, while in the case of alloy 2 after a fast reduction of $n$ there is a clear tendency of $n$ to decrease more slowly up to the fulfilment of the instability criterion. For the microstructures obtained at $200^{\circ} \mathrm{C}$ the situation completely differs from that previously described at higher transformation temperatures. Both alloys have some relevant features in common, such as a high increase of $n$ during the first stages of plastic deformation followed by a drastic drop that ends at low levels of plastic deformation.

Comparing $V_{\gamma_{\mathrm{F}}}$ calculations and total elongations results in 


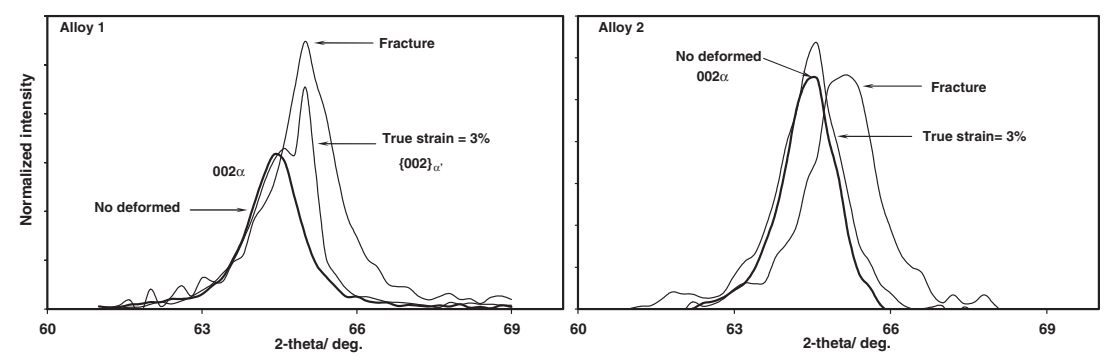

Fig. 7 Effect of deformation on $022_{\alpha}$ X-ray diffraction peak for the bainitic microstructure formed at $200^{\circ} \mathrm{C}$ in both alloys.

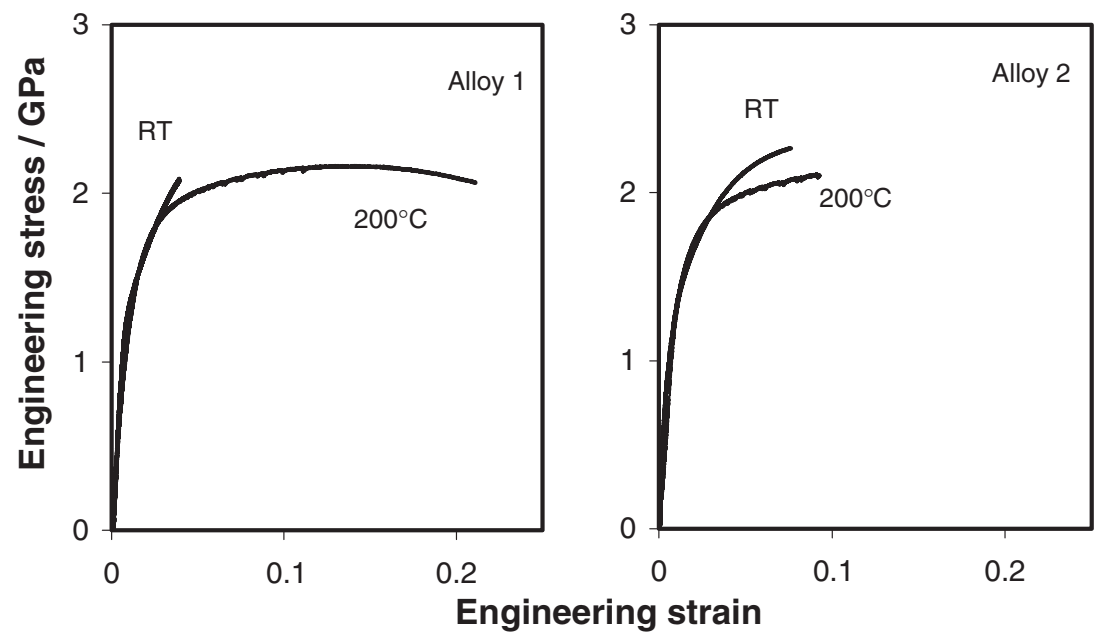

Fig. 8 Engineering stress-strain curves at room temperature and $200^{\circ} \mathrm{C}$ of microstructures obtained after transformation at $200^{\circ} \mathrm{C}$.

Tables 2 and 3, it can be deduced that morphology is not a strong factor for the control of the mechanical stability of the retained austenite, except for the case of the $300^{\circ} \mathrm{C}$ microstructure, where alloy 1 with $V_{\gamma_{\mathrm{F}}}=0.11$ has a total elongation of $29 \%$ whereas alloy 2 with $V_{\gamma \mathrm{F}}=0.09$ exhibits a total elongation of $27 \%$. This situation changes at 200 and $250^{\circ} \mathrm{C}$. At $200^{\circ} \mathrm{C}$, a higher fraction of thin films does not lead to higher total elongations, whereas at $250^{\circ} \mathrm{C}$ the same fraction of $V_{\gamma_{\mathrm{F}}}=0.12$ leads to different levels of total elongation $\left(\varepsilon_{\mathrm{T}}\right)$, see Tables 2 and 3. This seems to suggest that the chemical composition is an important factor controlling the mechanical stability of retained austenite. Thus, and according to Table 2, the retained austenite in alloy 2 is intrinsically more stable that in alloy 1 , or equivalently, lower $M_{\mathrm{d}}$ temperatures due to higher $\mathrm{C}$ and $\mathrm{Al}$ content.

This is supported by the profile evolution of the $002_{\alpha}$ peak at different deformation stages, i.e., no deformation, $3 \%$ true strain and fractured specimen, as shown in Fig. 7. In alloy 1 a martensite peak, $\{002\}_{\alpha^{\prime}}$, appears in the spectra after a deformation of $3 \%$ true strain, indicative that TRIP effect has effectively started. This does not occur in alloy 2 where martensite has not yet appeared. It is worth important to notice that according to the X-ray analysis on fracture surfaces of tensile specimens no austenite is present in any of the cases.

These observations and the knowledge that there is a correlation between the shape of $n v s$. true strain curves and the rate at which retained austenite transforms to martensite under strain, a possible explanation of the mechanisms ocurring during tensile deformation can be formulated. ${ }^{21,27-30)}$ The $200^{\circ} \mathrm{C}$ microstructures, with low fractions and lowest stability of the austenite (high $M_{\mathrm{d}}$ temperatures), rapidly transform at very small strains. As a result, there is little benefit of the strain induced transformation. The situation changes as the fraction of more stable austenite increases in the microstructure (low $M_{\mathrm{d}}$ temperatures), Fig. 6. In alloy 1 the $250^{\circ} \mathrm{C}$ retained austenite starts to transform immediately after the initial maximum $n$ and transformation proceeds until the instability criterion is reached, while in alloy 2 it starts to transform later, since the austenite is mechanically more stable. It should be noted that although both alloys have the same austenite fraction, the total elongation of alloy 2 is $10 \%$ smaller than that of alloy 1 . It is suggested that this is due to the fact that the chemical composition of retained austenite in alloy 2 makes it mechanically too stable. High fractions of very stable austenite are present at $300^{\circ} \mathrm{C}$ microstructures for both alloys. As a result, transformation starts well after the maximum $n$ and continues progressively up to necking. Alloy 2 contains $\sim 10 \%$ more of more stable retained austenite than alloy 1 , even though the total elongation of alloy 2 is slightly smaller than that of alloy 1 , Table 3 , supporting the idea that the retained austenite in this alloy is too stable.

Theoretical calculations presented in Fig. 2(b) suggest that the mechanical stability of austenite increases with the testing temperature. Therefore to prove this hypothesis, a series of tensile tests at $200^{\circ} \mathrm{C}$ were carried out on microstructures obtained by transformation at $200^{\circ} \mathrm{C}$. If the retained austenite 

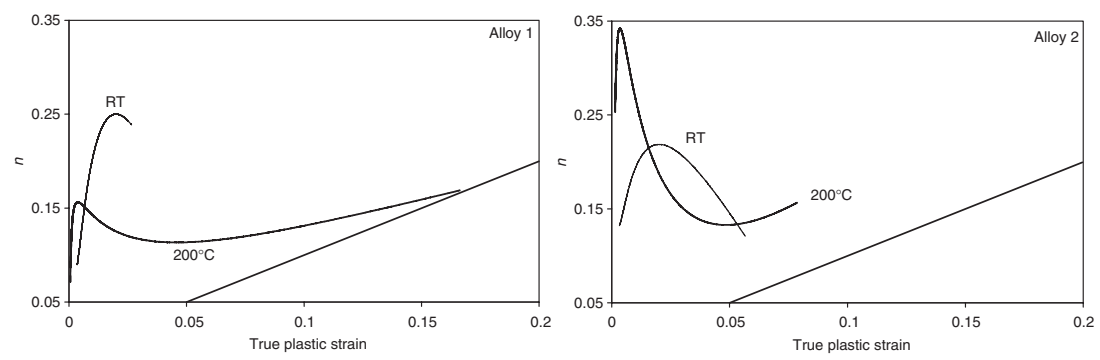

Fig. 9 Curves of the incremental work hardening exponent, $n$, of bainitic microstructures obtained by transformation at $200^{\circ} \mathrm{C}$ and tested at room temperature $(R T)$ and $200^{\circ} \mathrm{C}$. The straight line represents the instability criterion.

Table 4 Summary of experimental data from tensile test at $200^{\circ} \mathrm{C}$, in microstructures obtained after bainite transformation at $200^{\circ} \mathrm{C}$.

\begin{tabular}{cccc}
\hline & $Y S / \mathrm{GPa}$ & $U T S / \mathrm{GPa}$ & $\varepsilon_{\mathrm{T}} / \%$ \\
\hline Alloy 1 & 1.17 & 2.16 & 21 \\
\hline Alloy 2 & 1.1 & 2.09 & 10 \\
\hline
\end{tabular}

present in alloy 2 is too stable, as it is suggested, these high temperature tests would not introduce any substantial improvement of the total elongation in alloy 2. Figure 8 shows the measured strain-stress curves, from tensile tests at $200^{\circ} \mathrm{C}$, of microstructures obtained following transformation at $200^{\circ} \mathrm{C}$ for both alloys. The results obtained in this way are represented in Table 4. The $Y S$ has decreased in both alloys, as expected, about $300 \mathrm{MPa}$, and the UTS remains nearly unchanged. Regarding total elongation, significant differences are found between both steels. In alloy 1 increasing the test temperature produces an increase of the total elongation by 17 percentage units, while for the $\mathrm{Co}-\mathrm{Al}$ alloy the increase is less than 2 percentage units, see Table 4. Following the evolution of the incremental work hardening in Fig. 9, it is possible to assure that in both alloys retained austenite becomes more stable when compared with the room temperature experiments. After an initial rapid increase to high $n$ values and subsequent decrease, both alloys exhibit, at about 0.045 of true plastic strain, a minimum prior to a continuous increase. These results confirm that the retained austenite in alloy 2 is indeed mechanically too stable, which inhibits taking full advantage of its beneficial effect on ductility.

\section{Conclusions}

High-carbon, silicon-rich steels with bainitic microstructures obtained by transformation at very low temperatures (200-300 ${ }^{\circ} \mathrm{C}$ ) were tested in order to characterise their mechanical properties. The obtained microstructures exhibit an extraordinary combination of tensile properties, which has never before been achieved in bainitic steels. While strength is mainly controlled by the fine ferrite plate thickness and its dislocation density, ductility is controlled by the amount of retained austenite and its capability of enhancing total elongation by incrementing strain hardening. In this sense, the desirable situation is that of a mechanically stable austenite, but it has been shown that a too stable austenite is no guarantee for better results. It was also demonstrated that the mechanical stability of the retained austenite present in these microstructures is mainly determined by its chemical composition, or the ability of decreasing $M_{\mathrm{d}}$ temperature, rather than its morphology.

In any case, the ductility levels achieved, 4.6-29\% in total elongation, are extraordinary given the strength levels reported, up to $2.2 \mathrm{GPa}$.

\section{Acknowledgements}

The authors acknowledge financial support from the Spanish Ministerio de Ciencia y Tecnología in the form of a Ramón y Cajal contract (RyC 2002/2004). Some of this work was carried out under the auspices of an EPSRC/MOD sponsored project on bainitic steels at the University of Cambridge; we are extremely grateful for this support over a period of three years. We also would like to express our special acknowledgement to Prof. H. K. D. H. Bhadeshia for fruitful discussions.

\section{REFERENCES}

1) C. Garcia-Mateo, F. G. Caballero and H. K. D. H. Bhadeshia: ISIJ Int. 43 (2003) 1238-1243.

2) C. Garcia-Mateo, F. G. Caballero and H. K. D. H. Bhadeshia: J. Phys. IV France 112 (2003) 285-288.

3) O. Matsumura, Y. Sakuma, Y. Ishii and J. Zhao: ISIJ Int. 32 (1992) 1110-1116.

4) C. Garcia-Mateo, F. G. Caballero and H. K. D. H. Bhadeshia: ISIJ Int. 43 (2003) 1821-1825.

5) M. J. J. Dickson: J. Appl. Crystallogr. 2 (1969) 176-180.

6) D. J. Dyson and B. Holmes: J. Iron Steel Inst. 208 (1970) 469-474.

7) T. Sourmail and C. Garcia-Mateo: Comp. Mater. Sci. 34 (2005) 213218.

8) http://www.thomas-sourmail.org/martensite.html.

9) M. Y. Sherif, C. Garcia-Mateo, T. Sourmail and H. K. D. H. Bhadeshia: Mater. Sci. Technol. 20 (2004) 319-322.

10) MTDATA: Phase diagram calculation software, (National Physical Laboratory, Teddington, UK, 2004).

11) H. K. D. H. Bhadeshia: Bainite in Steels. Transformation, microstructure and properties, 2nd Edition (The Institute of Materials, London, 2001).

12) C. Garcia-Mateo and F. G. Caballero: Ultra-High-Strength Bainitic Steels. Submitted for publication in ISIJ Int., February 2005.

13) C. Garcia-Mateo, M. Peet, F. G. Caballero and H. K. D. H. Bhadeshia: Mater. Sci. Technol. 20 (2004) 814-818.

14) M. Peet, S. S Babu, M. K. Miller and H. K. D. H. Bhadeshia: Scr. Mater. 50 (2004) 1277-1281.

15) H. K. D. H. Bhadeshia and A. R. Waugh: Proc. of the International Solid-Solid Phase Transformations Conference, ed. by The Metallurgical Society of the A.I.M.E (Warrendale, PA, USA 1998) 993-998. 
16) H. K. D. H. Bhadeshia and A. R. Waugh: Acta Metall. 30 (1982) 775784.

17) H. K. D. H. Bhadeshia and D. V. Edmonds: Met. Sci. 17 (1983) 411419.

18) C. A. N. Lanzilloto and F. B. Pickering: Met. Sci. 16 (1982) 371-382.

19) N. K. Ballinger and T. Gladman: Metal. Sci. 3 (1981) 95-108.

20) H. K. D. K. Bhadeshia and D. V. Edmonds: Metall. Trans. A 10 (1979) 895-907.

21) P. J. Jaques, E. Girault, A. Mertens, B. Verlinden and F. Delanny: ISIJ Int. 41 (2001) 1068-1074.

22) K. Nohara, Y. Ono and N. Ohashi: J. ISIJ 63 (1977) 212-222.

23) F. G. Caballero, H. K. D. H. Bhadeshia, K. J. A. Mawella, D. G. Jones and P. Brown: Mater. Sci. Technol. 17 (2001) 517-522.

24) H. K. D. H. Bhadeshia and D. V. Edmonds: Met. Sci. 17 (1983) 420-
425.

25) V. T. T. Miihkinen and D. V. Edmonds: Mater. Sci. Technol. 3 (1987) $432-440$.

26) R. W. K. Honeycombe and H. K. D. H. Bhadeshia: Steels Microstructure and Properties, 2nd ed. (Edward Arnold, London 1995) 311315.

27) P. J. Jaques, E. Girault, Ph. Harlet and F. Delannay: ISIJ Int. 41 (2001) 1061-1067.

28) A. Itami, M. Takahashi and K. Ushioda: ISIJ Int. 35 (1995) 1121-1127.

29) K. Sugimoto, M. Kobayashi and S. Hashimoto: Metall. Trans. 23A (1992) 3085-3091.

30) Y. Sakuma, D. K. Matlock and G. Krauss: Metall. Trans. 23A (1992) 1233-1241. 